\title{
Conductive deafness-ptosis-skeletal anomalies syndrome
}

INSERM

\section{Source}

INSERM. (1999). Orphanet: an online rare disease and orphan drug data base. Conductive deafness-ptosis-skeletal anomalies syndrome. ORPHA:3236

Conductive deafness-ptosis-skeletal anomalies syndrome is a rare, genetic ectodermal dysplasia syndrome characterized by conductive hearing loss due to atresia of the external auditory canal and the middle ear complicated by chronic infection, ptosis and skeletal anomalies (internal rotation of hips, dislocation of the radial heads and fifth finger clinodactyly). In addition, a thin, pinched nose, delayed hair growth and dysplastic teeth are associated. There have been no further descriptions in the literature since 1978. 